\title{
The vesicle transport protein Vac1p is required for virulence of Candida albicans
}

\author{
Correspondence \\ Raimund Eck \\ raimund.eck@hki-jena.de
}

Received 4 May 2006

Revised 14 July 2006

Accepted 17 July 2006

\author{
Kathrin Franke, ${ }_{1}^{1}$ Monika Nguyen, ${ }^{2}$ Albert Härtl, ${ }^{2}$ Hans-Martin Dahse, ${ }^{2}$ \\ Georgia Vogl, ${ }^{3}$ Reinhard Würzner, ${ }^{3}$ Peter F. Zipfel, ${ }^{2}$ Waldemar Künkel ${ }^{1}$ \\ and Raimund Eck ${ }^{1}$
}
${ }^{1}$ University of Applied Sciences, Department of Medical Engineering, Carl-Zeiss-Promenade 2, D-07745 Jena, Germany
${ }^{2}$ Leibniz-Institute for Natural Products Research and Infection Biology/Hans-Knöll-Institute, Department of Infection Biology, Beutenbergstrasse 11, D-07745 Jena, Germany
${ }^{3}$ Department of Hygiene, Microbiology and Social Medicine, Fritz-Pregl-Strasse 3, A-6020 Innsbruck, Austria

\begin{abstract}
The putative vesicle transport protein Vac1p of the human pathogenic yeast Candida albicans plays an important role in virulence. To determine the cellular functions of Vac1p, a null mutant was generated by sequential disruption of both alleles. The vac1 null mutant strain showed defective endosomal vesicle transport, demonstrating a role of Vac1p in protein transport to the vacuole. Vac1p also contributes to resistance to metal ions, as the null mutant strain was hypersensitive to $\mathrm{Cu}^{2+}, \mathrm{Zn}^{2+}$ and $\mathrm{Ni}^{2+}$. In addition, the loss of Vac1p affected several virulence factors of $C$. albicans. In particular, the vac1 null mutant strain showed defective hyphal growth, even when hyphal formation was induced via different pathways. Furthermore, Vac1p affects chlamydospore formation, adherence to human vaginal epithelial cells, and the secretion of aspartyl proteinases (Saps). Avirulence in a mouse model of systemic infection of the vac1 null mutant strongly suggests that Vac1p of C. albicans is essential for pathogenicity. In summary, the Vac1p protein is required for several cellular pathways, in particular those that control virulence and pathogenicity.

Consequently, Vac1p is a novel and interesting target for antifungal drugs.
\end{abstract}

\section{INTRODUCTION}

The dimorphic yeast Candida albicans causes life-threatening infections, particularly in immunocompromised patients, as well as a variety of mucosal infections in healthy individuals (Odds, 1994). Present evidence suggests that several factors control virulence of C. albicans, including the ability to switch between different morphogenetic forms, adherence to host epithelial and endothelial cells, and secretion of proteinases and phospholipases (Cutler, 1991; Köhler \& Fink, 1996; Lo et al., 1997; Odds, 1994). So far, a number of virulence factors of $C$. albicans has been characterized. However, the mechanism that enables this opportunistic fungus to become pathogenic has not been unravelled yet. Several classical virulence factors have been identified so far; however, it seems relevant to analyse virulence-determining signalling pathways as well. These define the molecular steps during switching from the non-pathogenic commensal form to the life-threatening pathogenic form. Several signalling pathways have been

Abbreviations: CPY, carboxypeptidase Y; 5-FOA, 5-fluoroorotic acid; PI, phosphatidylinositol; Ptdlns(3)P, phosphatidylinositol 3-phosphate; Sap, secreted aspartyl proteinase. linked to virulence, including hyphal induction pathways (Ernst, 2000a, b), and the vacuolar transport pathways (Bruckmann et al., 2000, 2001; Eck et al., 2000; Palmer et al., 2003).

The phosphatidylinositol (PI) 3-kinase Vps34p of $C$. albicans is a key enzyme of the vacuolar protein transport, and is required for virulence. A vps34 null mutant strain shows several defects related to virulence, including avirulence in a mouse model of systemic candidiasis, inability to form hyphae on different solid media, delayed yeast-tohyphae transition in liquid media, hyperfilamentation under microaerophilic/embedded conditions, hypersensitivity to high temperature and hyperosmotic stress, and reduced adherence to human cells (Bruckmann et al., 2000; Eck et al., 2000). In addition, the vps34 null mutant displays enlarged and electron-transparent vacuoles (Bruckmann et al., 2001). The Vps34p protein of C. albicans interacts with Vma7p, a component of the Candida V-ATPase complex (Eck et al., 2005). vma7 null mutants are also avirulent (Poltermann et al., 2005). Moreover, the secretion of aspartyl proteinases (Saps) and the resistance to toxic metal ions and fungistatic compounds are decreased in the vps34 null mutant strain (Kitanovic et al., 2005). The Vps34p 
protein exhibits lipid kinase and autophosphorylation activity. The characterization of a specific Vps34p lipid kinase defective mutant strain showed that the lipid kinase activity is essential for the role of Vps34p in pathogenicity (Günther et al., 2005). Thus, lipid substrates of Vps34p, such as phosphatidylinositol 3-phosphate [PtdIns(3)P], are candidates to connect Vps34p signalling and virulence. Therefore, we speculated that the PtdIns(3)P-binding proteins Fablp and Vaclp play a role in virulence.

PtdIns(3)P-binding proteins were identified in the yeast Saccharomyces cerevisiae and in mammalian cells. They contain a conserved FYFE finger domain named after the first four identified FYFE finger proteins Fablp, YOTB, Vps27p and EEA1 (human homologous protein of Vaclp) (Burd \& Emr, 1998; Stenmark \& Aasland, 1999). In S. cerevisiae the binding protein Fablp functions downstream of Vps34p as a PI(3) 5-kinase, which regulates vacuolar membrane turnover through the production of PdtIns(3,5) $\mathrm{P}_{2}$ (Gary et al., 1998). The PtdIns(3)P-binding protein Vaclp functions in Golgi-to-endosome vesicular protein transport (Weisman \& Wicker, 1992). Because the lipid kinase function of Vps34p is essential for virulence of C. albicans, and the PdtIns(3)P-binding protein Fablp is not involved in virulence, we focused on the functions of another PdtIns(3)P-binding protein, namely Vaclp (Augsten et al., 2002; Günther et al., 2005).

In S. cerevisiae Vaclp is a peripheral membrane protein, which belongs to the class $\mathrm{D} v p s$ group, and plays a role in vesicle docking at the late endosome (multivesicular body). Mutations in the FYFE domain of the Vaclp protein result in mis-sorting of vacuolar proteins and temperaturesensitive growth (Burd et al., 1997). Vaclp is an essential component of the endosomal SNARE (SNAP receptor) complex, which is responsible for the interaction and fusion of Golgi-derived vesicles with the late endosome (Burd et al., 1997; Webb et al., 1997). Furthermore, Vaclp links the Vps34p-signalling pathway to the fusion of transport vesicles with the endosome (Burd \& Emr, 1998). This step is regulated by direct interaction with Rab GTPase signalling protein Vps21p; the fusion is mediated by Pep12p and Vps45p (Horazdovsky et al., 1994; Peterson et al., 1999; Peterson \& Emr, 2001; Tall et al., 1999). In addition, the class C $v p s$ proteins Vps18p and Vps11p interact with Vaclp (Peterson \& Emr, 2001; Srivastava et al., 2000).

In this paper we show that Vaclp of C. albicans contributes to virulence, and that a vac1 null mutant is avirulent. In addition, Vaclp affects several important virulence parameters, thus demonstrating that in $C$. albicans this PdtIns(3)P-binding protein acts as a central component of the virulence-determining Vps34p pathway.

\section{METHODS}

Strains and growth conditions. The $C$. albicans strains used in this study are listed in Table 1. Strains were grown in YPD medium [2\%(w/v) glucose, $2 \%(\mathrm{w} / \mathrm{v})$ peptone, $1 \%(\mathrm{w} / \mathrm{v})$ yeast extract], YP-sucrose medium $[2 \%(\mathrm{w} / \mathrm{v})$ sucrose, $2 \%(\mathrm{w} / \mathrm{v})$ peptone, $1 \%$ $(\mathrm{w} / \mathrm{v})$ yeast extract], SD medium $[0 \cdot 7 \%(\mathrm{w} / \mathrm{v})$ yeast nitrogen base without amino acids (Difco), $2 \%(\mathrm{w} / \mathrm{v})$ glucose, $1 \mathrm{M}$ sorbitol], YNB medium (SD without $1 \mathrm{M}$ sorbitol) or Sabouraud medium [2\% $(\mathrm{w} / \mathrm{v})$ glucose, $1 \%(\mathrm{w} / \mathrm{v})$ peptone (casein)] at $28^{\circ} \mathrm{C} . \mathrm{SD}$ and $\mathrm{YNB}$ were supplemented with $20 \mu \mathrm{g}$ uridine $\mathrm{ml}^{-1}$ for the growth of $\mathrm{Ura}^{-}$strains. Uridine auxotrophs were selected on YNB plates containing uridine and $1 \mathrm{mg}$ 5-fluoroorotic acid (5-FOA) $\mathrm{ml}^{-1}$ (Sigma). Growth was monitored by measuring optical density at $600 \mathrm{~nm}$ in a SpectraMax 190 spectrophotometer. To induce hyphal growth on solid medium, cells were grown overnight in YPD at $30{ }^{\circ} \mathrm{C}$, then washed with $0.9 \mathrm{M} \mathrm{NaCl}$, diluted and spread either on Spider plates $\left[1 \%(\mathrm{w} / \mathrm{v})\right.$ nutrient broth, $0 \cdot 2 \%(\mathrm{w} / \mathrm{v}) \mathrm{K}_{2} \mathrm{HPO}_{4}$, $1.35 \%(\mathrm{w} / \mathrm{v})$ agar, $1 \%(\mathrm{w} / \mathrm{v})$ mannitol] (Lee et al., 1975), or on YPD plates supplemented with $15 \%(\mathrm{w} / \mathrm{v})$ fetal calf serum (FCS) at a density of 20 to 100 cells per plate. Plates were incubated at $37^{\circ} \mathrm{C}$ for at least 7 days. Hyphal growth in liquid media was induced by diluting late exponential-phase cultures grown at $30{ }^{\circ} \mathrm{C}$ tenfold either into fresh YPD supplemented with $10 \%(\mathrm{w} / \mathrm{v})$ FCS, or into Spider medium at $37^{\circ} \mathrm{C}$. Sensitivities of the mutants to various metal ions were assayed on YPD plates supplemented with the appropriate salts. Escherichia coli XL-1 Blue \{supE44 hsdR17 recA1 endA1 gyrA46 thi relA1 lac $\mathrm{F}^{\prime}\left[\right.$ proAB $^{+}$lacl $^{\mathrm{q}} \Delta \mathrm{M} 15 \quad \mathrm{Tn} 10\left(\right.$ tet $\left.\left.\left.^{\mathrm{r}}\right)\right]\right\}$ (Stratagene) was used for cloning.

Construction of plasmids pV0, pV1 and pUCVU. The $5^{\prime}$ region of VAC1 was amplified by PCR using chromosomal DNA of $C$.

Table 1. Strains and plasmids

\begin{tabular}{|c|c|c|}
\hline Strain or plasmid & Genotype or description & Reference/source \\
\hline \multicolumn{3}{|l|}{ C. albicans } \\
\hline SC5314 & Wild-type & Fonzi \& Irwin (1993) \\
\hline CAI-4 & 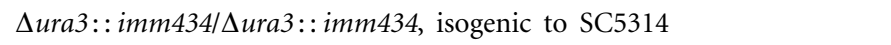 & Fonzi \& Irwin (1993) \\
\hline CV1 & 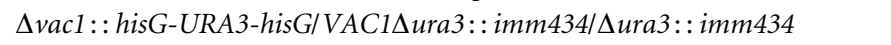 & This work \\
\hline CV2 & 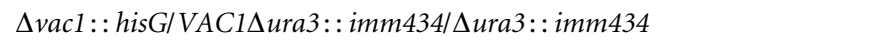 & This work \\
\hline CV3 & 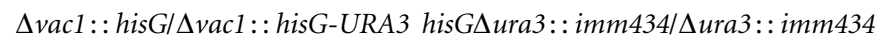 & This work \\
\hline CV4 & 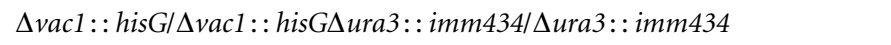 & This work \\
\hline CV5 & 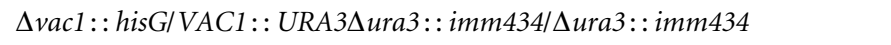 & This work \\
\hline \multicolumn{3}{|l|}{ Plasmids } \\
\hline pUC19 & Escherichia coli cloning vector & Yanisch-Perron et al. (1985) \\
\hline pMB7 & C. albicans gene disruption vector & Fonzi \& Irwin (1993) \\
\hline
\end{tabular}


albicans SC5314 as a template and primers 1 and 2. Primer 1: 5'GCGAGCTCGACGATATAACGGTTGTGTTG-3' (the underlined sequence is complementary to the genomic sequence, positions -144 to - 124, upstream of VAC1); primer 2: 5'-GCGGTACCTGTCGTGTCACAAAGGGTGC-3' (positions +166 to +146 ). The resulting 325 bp PCR product was SacI/KpnI-digested and cloned into the disruption vector pMB7, yielding pV0 (Fonzi \& Irwin, 1993). Primers 3 and 4 were used to amplify the $3^{\prime}$ region. Primer 3 : 5'-ACGCGTCGACCAAAGCGAGACGGTTTGATG-3' (positions +1232 to +1252 ); primer 4: 5'-GCCTGCAGCAAGCAGAACAAGTTATGACAGC-3' (positions -178 to -156 ; downstream of VAC1) yielded a 311 bp product, which was digested with SalI and PstI and

(a)

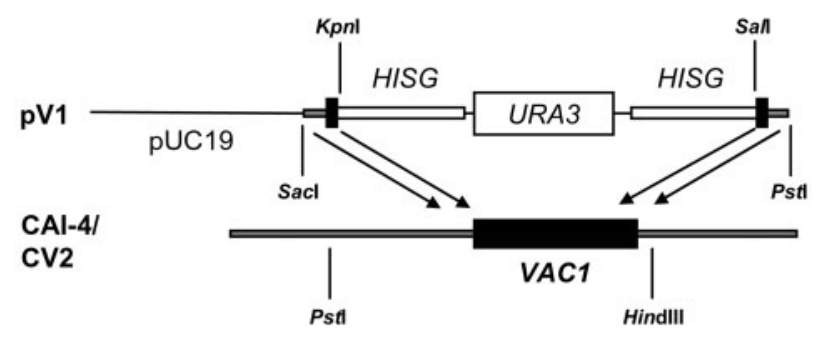

(b)

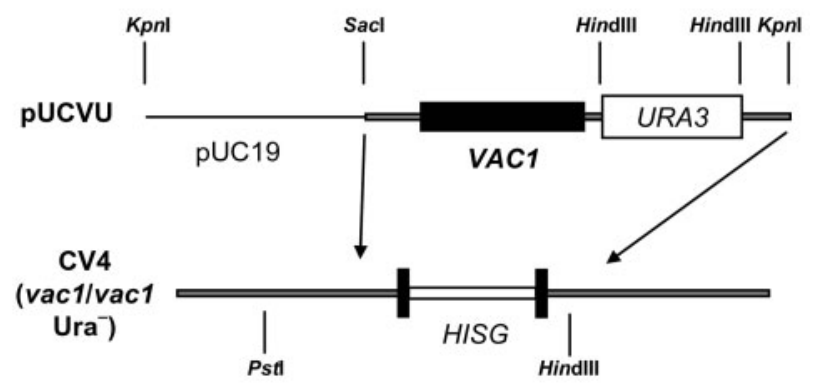

(c)

wt CV1 CV2 CV3 CV4 CV5

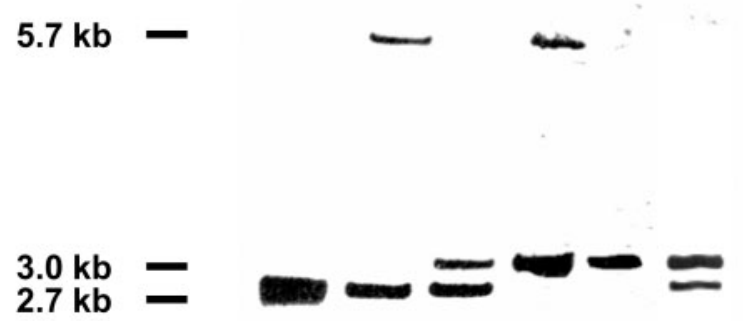

cloned into plasmid pV0, resulting in pV1 (Fig. 1a). For gene disruption, plasmid $\mathrm{pV} 1$ was cut with SacI and PstI. The digested plasmid $\mathrm{pV} 1$ was transformed to C. albicans. For homologous reintegration of the VAC1 gene, VAC1 was amplified by PCR with primer 5 [5'-GCGAGCTCTGAGAGTAATCCAAAGCAGTTAC-3' ( -695 to -672 , upstream of $V A C 1)$ ] and primer 6 [5'-GCGGTACCACCCATGCGTGTCCAACAACT-3' ( -905 to -884 , downstream of VAC1)]. The 2961 bp PCR product was restricted with SacI/KpnI and cloned into pUC19 (Yanisch-Perron et al., 1985), resulting in pUCV. The URA3 gene was amplified with primer $75^{\prime}-$ ACGCCCAAGGAATTGATTTGGATGGTATA-3' (-411 to -393 , upstream of URA3)] and primer 8 [5'-ACGCCCTTGGACCACCTTTGATTGTAAATA-3' $(-120$ to -101 , downstream of URA3)]. The 1364 bp PCR product was restricted with StyI and cloned into the StyI site (positions -244 to -249 , upstream of VAC1) of pUCV, resulting in pUCVU. After digestion of pUCVU with SacI and $K p n \mathrm{I}$ a $4.3 \mathrm{~kb}$ insert was isolated that harbours the VAC1 gene, upstream as well as downstream regions for homologous recombination, and the URA3 gene as selectable marker.

Transformation of C. albicans and selection of Ura ${ }^{-}$auxotrophs. The methods were carried out according to the procedures described previously (Boeke et al., 1984; Eck et al., 1997).

Disruption and reintegration of VAC1. To disrupt the VAC1 gene, the previously described hisG-URA3-hisG cassette was used in a multistep procedure (Fonzi \& Irwin, 1993). A $4.6 \mathrm{~kb}$ SacI-PstI fragment of $\mathrm{pV} 1$ containing the URA-blaster flanked by short sequences from the upstream and downstream sequences of VAC1 and portions of the promoter and terminator, respectively, was used to transform C. albicans $\mathrm{Ura}^{-}$strain CAI-4. To confirm proper deletion of the VAC1 ORF (1338 bp, 445 aa, Stanford's Candida albicans sequencing project Assembly 19, ORF19.5662 on Contig231; http:// sequence-www.stanford.edu/group/candida/index.html), the resulting $\mathrm{Ura}^{+}$transformants were examined by Southern analysis using HindIII/PstI-digested chromosomal DNA and a labelled $300 \mathrm{bp}$ SacI-KpnI fragment of $\mathrm{pV} 1$ as probe. Southern hybridization was also applied to evaluate segregants and transformants of the later disruption steps, according to standard protocols. In the first step one VAC1 allele was replaced by the hisG-URA3-hisG cassette (CV1). Strain CV1 was plated on 5-FOA-containing medium for

Fig. 1. Disruption and reintegration of VAC1 gene in C. albicans. (a) Restriction map of the plasmid $\mathrm{pV} 1$, illustrating the strategy for disruption of $V A C 1$. The $5^{\prime}$ and $3^{\prime}$ regions of $V A C 1$ were obtained by $\mathrm{PCR}$, and cloned in front or behind of the hisG-URA3-hisG cassette $(4 \cdot 1 \mathrm{~kb}$, thick open boxes) in the disruption vector pMB-7. The VAC1 gene of C. albicans CAl-4 or $\mathrm{CV} 2$ was disrupted by integration/recombination of the Sacl-Pstl fragment of $\mathrm{pV} 1$ into the chromosome. Vertical black lines show the location of restriction sites in (a) and (b). (b) Restriction map of the plasmid pUCVU illustrating the strategy for reintegration of $V A C 1$. A $1.3 \mathrm{~kb}$ Hindlll fragment containing the URA3 gene (thick open box) was cloned behind VAC1. A Sacl-Kpnl fragment containing VAC1 and URA3 integrates into original locus of VAC1 in CV4. (c) Southern analysis of Hindlll/ Pstl-digested chromosomal DNA from the following C. albicans strains: parental wild-type strain CAl-4 (lane 1), heterozygous mutant strain CV1 (VAC1/vac1::hisG-URA3-hisG) (lane 2), heterozygous mutant strain CV2 (VAC1/vac1::hisG) (lane 3), null mutant strain CV3 (vac1:: hisG-URA3-hisG/vac1::hisG) (lane 4), null mutant strain CV4 (vac1::hisG/vac1:: hisG) (lane 5), and revertant strain CV5 (vac1::hisG/VAC1-URA3) (lane 6). The blot was hybridized with non-radioactive labelled Sacl$K p n l$ insert of plasmid pV1 (a). 
isolation of $\mathrm{Ura}^{-}$segregants (CV2). A second transformation with the same disruption construct led to the isolation of a vacl null mutant strain (CV3). Again, $\mathrm{Ura}^{-}{ }^{-}$segregants were selected (CV4).

VAC1 was reintroduced into the null mutant strain CV4 by transformation with the $4.3 \mathrm{~kb} \mathrm{SacI} / K p n \mathrm{I}$ insert of pUCVU. Chromosomal DNA from selected clones was digested with HindIII/PstI and analysed by Southern blotting and hybridization (CV5).

Fluorescent labelling with FM4-64 and microscopy. Yeast cells were stained with the dye FM4-64 as described previously (Günther et al., 2005; Vida \& Emr, 1995). For microscopy, cells were placed on slides that were covered with agarose. Transport of FM4-64 was visualized microscopically using a BP510-550 excitation filter (U-MWG2), BA590 beam splitter and DM570 emission filter (Olympus BX51TF).

Hyphal induction within agar matrix. For filamentous growth within an agar matrix the various $C$. albicans strains were grown overnight in YPD, diluted to a concentration of $5 \times 10^{6} \mathrm{cells} \mathrm{ml}^{-1}$, and cultivated for $4 \mathrm{~h}$ at $30^{\circ} \mathrm{C}$. Then $100 \mu \mathrm{l}$ of the diluted cells $\left(10^{3}\right.$ cells $\left.\mathrm{ml}^{-1}\right)$ was mixed in YP-sucrose agar (YP-sucrose medium supplemented with $2 \%$ agar), plated, and incubated for $120 \mathrm{~h}$ at $22^{\circ} \mathrm{C}$. Colonies were examined microscopically, and the percentage of filamentous colonies was determined.

Hyphal induction by growth at neutral pH. C. albicans cells (100 $\mu \mathrm{l}$ of an overnight culture) were added to $20 \mathrm{ml}$ acidic Soll's medium (Swoboda et al., 1994), $\mathrm{pH} 4 \cdot 5$, and incubated for $12 \mathrm{~h}$ at $30^{\circ} \mathrm{C}$. Then $20 \mathrm{ml}$ neutral Soll's medium, $\mathrm{pH} 6 \cdot 5$, was supplemented with $500 \mu \mathrm{l}$ from the acidic culture. The hyphal growing cells were counted using a microscope.

Chlamydospore formation. Rice agar $(2 \%, \mathrm{w} / \mathrm{v}$, agar; $40 \mathrm{~g}$ rice per litre $\mathrm{H}_{2} \mathrm{O}$ ) was melted and after a short centrifugation the agar was plated onto a slide. C. albicans cells from an overnight culture were streaked onto this agar and covered with a coverslip. The slides were incubated in the dark at $25^{\circ} \mathrm{C}$ in a damp environment. Chlamydospore formation was evaluated microscopically after $96 \mathrm{~h}$. For growth in liquid medium the rice agar was diluted $1: 1(\mathrm{v} / \mathrm{v})$ with water.

Adherence assays. C. albicans cells obtained from an overnight YPD culture at $30^{\circ} \mathrm{C}$ were diluted into $20 \mathrm{ml}$ fresh YPD medium (pH 6.0) to a concentration of $5 \times 10^{5}$ cells $\mathrm{ml}^{-1}$. Following incubation for $16 \mathrm{~h}$ at $30^{\circ} \mathrm{C}$, the cells were washed and diluted in YPD medium, $\mathrm{pH} 4 \cdot 5$, to a concentration of $2 \times 10^{7}$ cells $\mathrm{ml}^{-1}$. Human vaginal SK-LMS-1 cells (leiomyosarcosoma) were cultivated in microtest plates in RPMI medium (Serva) to a concentration of $10^{4}$ cells per well. The tissue culture cells were washed with PBS (140 mM NaCl, $2 \mathrm{mM} \mathrm{KCl,} 10 \mathrm{mM} \mathrm{Na} \mathrm{HPO}_{4}, 1 \cdot 8 \mathrm{mM} \mathrm{KH_{2 }} \mathrm{PO}_{4}$, $\mathrm{pH} 7 \cdot 2$ ), and then $4 \times 10^{6} \mathrm{C}$. albicans cells were added to each well. After cultivation at $37^{\circ} \mathrm{C}$ for $2 \mathrm{~h}, \mathrm{C}$. albicans cells were stained with Calcofluor white $\left(12.5 \mu \mathrm{g} \mathrm{ml}^{-1}\right.$; Sigma) for $30 \mathrm{~min}$, and nonadherent $C$. albicans cells were removed by washing with PBS. Finally, the fraction of adherent fluorescent yeast cells was determined in a fluorescence reader, using $360 \mathrm{~nm}$ for excitation and $460 \mathrm{~nm}$ for emission (FluoroScan, Labsystems). The wild-type C. albicans strain SC5314 was set to $100 \%$. For statistical analysis Student's $t$-test was used. A $P$ value $\leqslant 0 \cdot 025$ was considered significant.

Sap ELISA assay. This assay was carried out essentially as described previously (Kitanovic et al., 2005). The primary mouse antibody (FX 7-10, which preferentially detects Sap2p but also other Saps) was kindly provided by Dr Borg-von Zeppelin, Göttingen, Germany.

Virulence studies. Male outbred NMRI mice (HarlanWinkelmann), 6 weeks old, were housed at five per cage and checked daily. The various strains of $C$. albicans were grown in Sabouraud dextrose [glucose] broth at $28^{\circ} \mathrm{C}$ until late exponential phase. Cells were washed three times and resuspended in $0.9 \%$ $\mathrm{NaCl}$. Samples $(200 \mu \mathrm{l})$ of suspension containing $5 \times 10^{6}$ cells were used to infect immunocompetent mice by intravenous injection into the lateral tail vein. Survival of the animals was monitored for 20 days. For comparison of survival curves the log-rank test was used (Peto et al., 1977). A $P$ value $\leqslant 0 \cdot 05$ was considered significant.

\section{RESULTS}

\section{Disruption and reintroduction of VAC1}

A vac1 null mutant strain of C. albicans CAI-4 was generated in order to characterize the function of Vaclp as a potential vacuolar vesicle transport protein. The $4.6 \mathrm{~kb}$ SacI-Pst fragment of VAC1 contained in plasmid pV1 (Fig. 1a) was used to transform the $C$. albicans $\mathrm{Ura}^{-}$strain CAI-4. Southern blot analysis of $C$. albicans DNA from a heterozygous vac1 mutant (CV1) identified two bands (Fig. 1c). The $2.7 \mathrm{~kb}$ fragment represents the VAC1 wild-type allele (Fig. 1c, lane 1 ), while the $5 \cdot 7 \mathrm{~kb}$ fragment can be identified as the hisG-URA3-hisG cassette that replaced the VAC1 gene (lane 2). The excision of one copy of his G and the URA3 gene in the Ura ${ }^{-}$derivatives results in the $2.9 \mathrm{~kb}$ band (CV2, lane 3 ). A second transformation with the same disruption construct generated $v a c 1$ null mutant strain CV3. The loss of the $2.7 \mathrm{~kb}$ wild-type fragment and the presence of $5.7 \mathrm{~kb}$ and $2.9 \mathrm{~kb}$ bands are consistent with the replacement of the second VAC1 allele (lane 4). Southern blot analysis of a representative $\mathrm{Ura}^{-}$segregant identified a $2.9 \mathrm{~kb}$ band that represents two his $G$ disrupted alleles (CV4, lane 5). For reintegration of $V A C 1$, the $4 \cdot 3 \mathrm{~kb} S a c \mathrm{I}-K p n \mathrm{I}$ fragment of plasmid pUCVU (VAC1 and URA3) was used to transform strain CV4. Ura ${ }^{+}$clones were selected, and proper introduction of VAC1 and URA3 was recognized by the appearance of a $3.6 \mathrm{~kb}$ PstI-HindIII fragment, which represents the integrated VAC1 and URA3 genes (CV5, lane 6).

\section{Vac1p is required for the transport and fusion of prevacuolar endocytic compartments}

Vps34p is required for the transport of prevacuolar vesicles to the vacuole in both $C$. albicans and $S$. cerevisiae. This function plays a role in endocytosis and in the CPY (carboxypeptidase Y) protein transport pathway from the late Golgi to the vacuole (Bruckmann et al., 2001; Wurmser \& Emr, 1998). This action can be analysed by following the distribution of the fluorescent lipophilic dye FM4-64, as it is transported in yeast cells via the endocytotic uptake and vesicle-mediated transport to the vacuole (Vida \& Emr, 1995). The endocytic transport of the lipophilic dye was analysed in the vac1 null mutant strain CV3 by fluorescence microscopy (Fig. 2). The null mutant strain showed weak staining of the vacuolar membrane, whereas prevacuolar endocytic compartments in the cytoplasm were stained. The heterozygous mutant strain $\mathrm{CV} 1$ and the revertant strain CV5 showed similar staining to the wild-type strain SC5314, where the dye is contained in the vacuolar membrane and 
FM 4-64
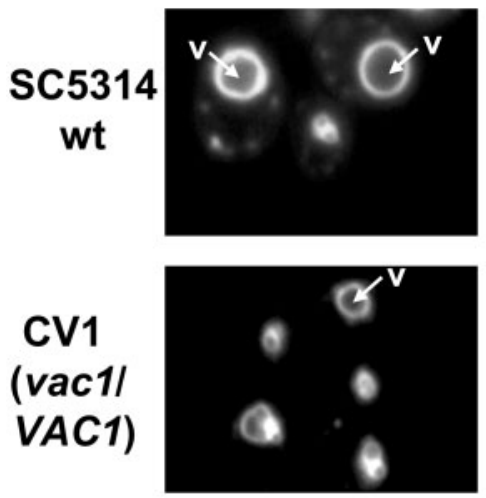

CV3 (vac1)
vac1)
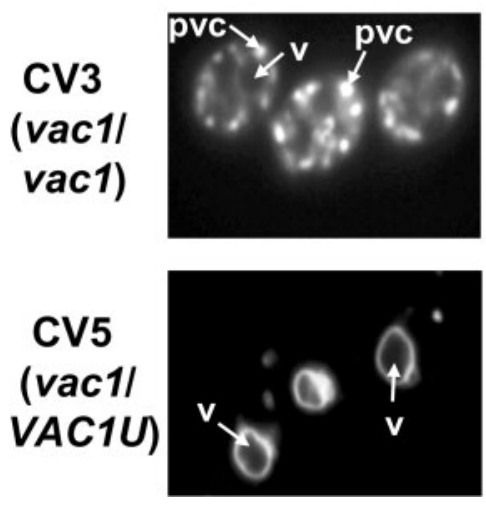

DIC
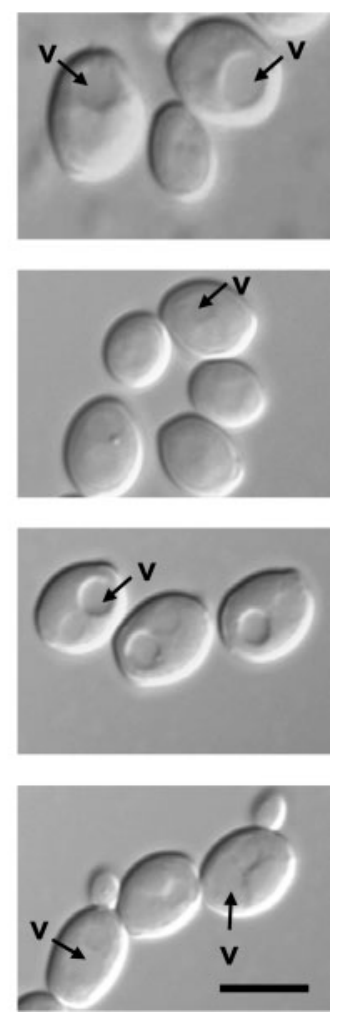

Fig. 2. Characterization of the endocytic protein transport pathway by following the distribution of the lipophilic dye FM4-64 in C. albicans wild-type strain SC5314, heterozygous mutant strain CV1, vac1 null mutant strain CV3, and VAC1 revertant strain CV5. Cells were pulsed for $30 \mathrm{~min}$ with the fluorescent endocytic dye FM4-64 and then chased for 60 min. Fluorescence microscopy and differential interference contrast (DIC) microscopy show that the lyophilic dye FM4-64 accumulated in mutant strain $\mathrm{CV} 3$ in presumptive prevacuolar compartments (arrows) in the cytoplasm. The wild-type strain SC5314, the heterozygous mutant strain $\mathrm{CV} 1$ and the revertant strain $\mathrm{CV} 5$ show typical ring staining pattern of the vacuole membrane. $\mathrm{v}$, vacuoles; pvc, prevacuolar compartments. Bar, $10 \mu \mathrm{m}$ (applies to all photographs).

shows a typical ring staining pattern. Therefore we conclude that deletion of VAC1 in the C. albicans vac1 null mutant strain results in defective transport/fusion functionality of the prevacuolar endocytic vesicle.

\section{Role of Vac1p in metal ion homeostasis}

Metal ion homeostasis is affected in the vps34 null mutant. Therefore, we investigated the influence of metal ions on the growth of the $C$. albicans vac1 null mutant strain, which would indicate a role of Vaclp in metal ion homeostasis. C. albicans strains were grown on solid medium supplemented with $\mathrm{Cu}^{2+}, \mathrm{Zn}^{2+}$ or $\mathrm{Ni}^{2+}$. The vacl null mutant strain CV3 showed inhibited growth in the presence of $\mathrm{CuCl}_{2}$ at a concentration of $8 \mathrm{mM}, \mathrm{ZnCl}_{2}$ at $15 \mathrm{mM}$, and
$\mathrm{NiSO}_{4}$ at $4 \mathrm{mM}$. The heterozygous mutant strain $\mathrm{CV} 1$ and the revertant strain CV5 were similar in growth to the wildtype strain SC5314. The vac1 null mutant showed increased sensitivity to high concentrations of the tested metal ions, therefore demonstrating a role of Vaclp in resistance to metal ions (Fig. 3).

\section{Vac1p influences dimorphic growth of C. albicans}

Dimorphism is considered an important virulence factor of C. albicans (Lo et al., 1997). Filamentous growth of $C$. albicans is induced by several signalling pathways that are triggered by several environmental signals, and which are activated experimentally by Spider medium supplemented with mannitol as a carbon source, serum, microaerophilic conditions, growth in a solid agar matrix, and $\mathrm{pH}$-shift. These various methods were used to induce hyphal growth of the vac1 null mutant strain CV3. When solid Spider medium was used for hyphal induction, the colonies of the
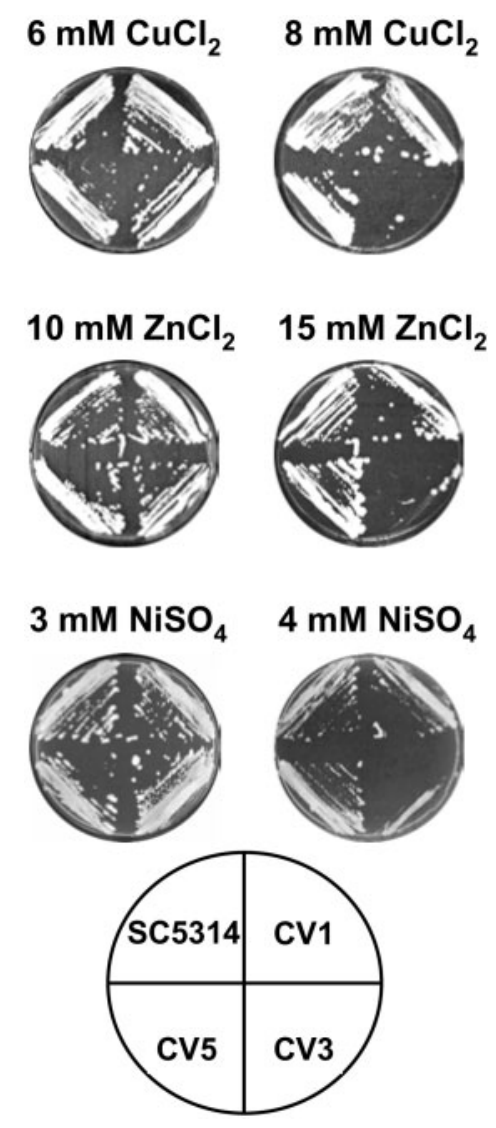

Fig. 3. The C. albicans vac1 null mutant shows increased sensitivity to metal ions. The growth of wild-type strain SC5314,

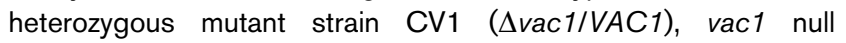
mutant strain CV3 $(\Delta v a c 1 / \Delta v a c 1)$, and $V A C 1$ revertant strain CV5 (Avac1/VAC1-URA3) in the presence of $\mathrm{CuCl}_{2}, \mathrm{ZnCl}_{2}$ and $\mathrm{NiSO}_{4}$ is shown. 
(a)
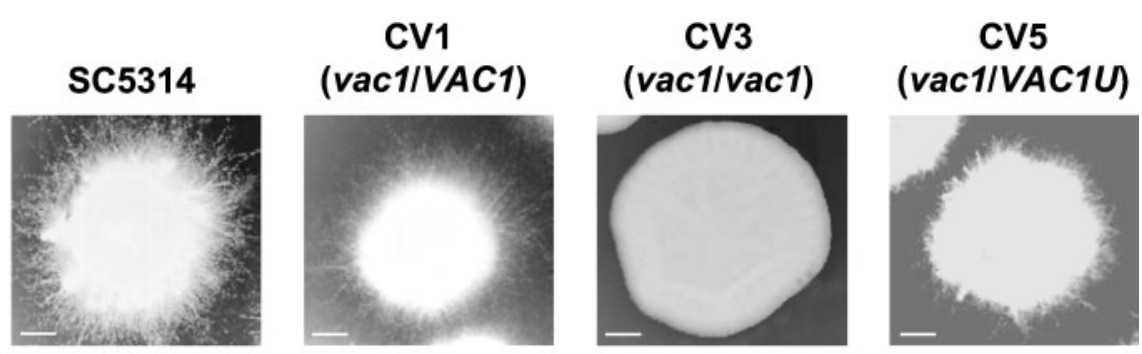

(b)
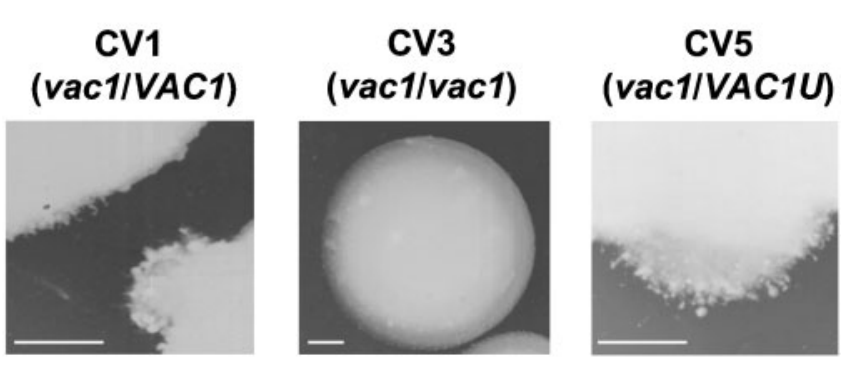

(c)
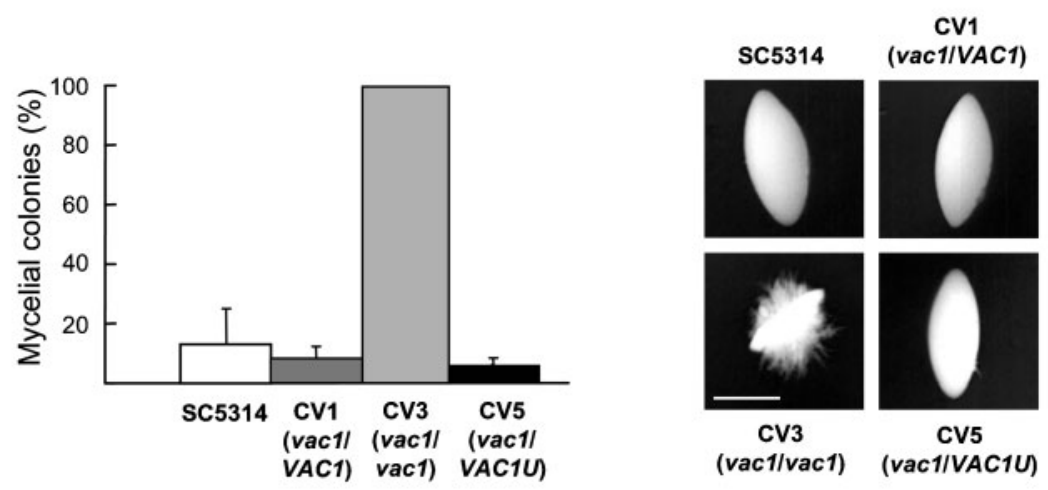

(d)
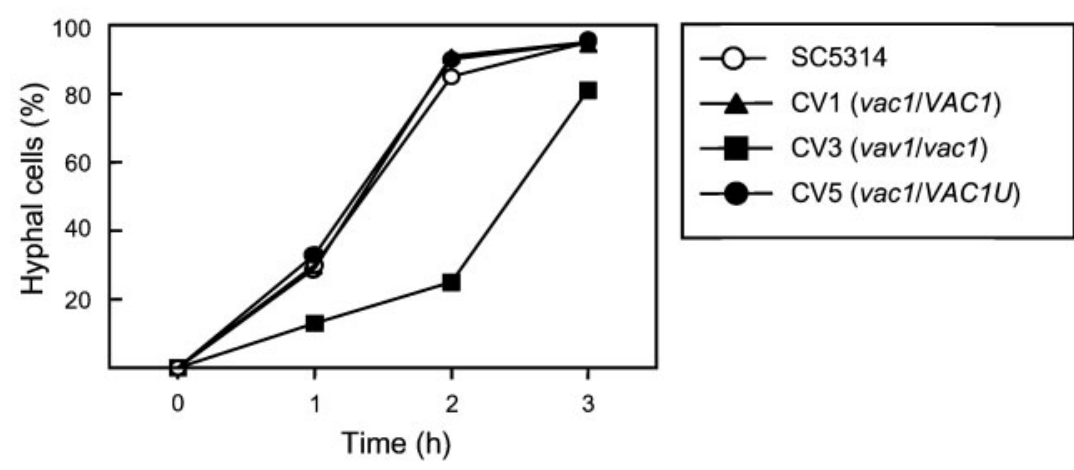

Fig. 4. Vac1p is involved in hyphal development. Hyphal growth of $C$. albicans wild-type strain SC5314, heterozygous mutant strain CV1, vac1 null mutant strain CV3, and VAC1 revertant strain CV5 using solid Spider medium containing mannitol as carbon source (a), solid medium supplemented with $20 \%$ serum (b), under microaerophilic/embedded conditions in an agar matrix (c), and after shift of $\mathrm{pH}$ from 4.5 to 6.5 (d).

vac1 null mutant strain did not form mycelial structures. However, the colonies of the heterozygous mutant strain $\mathrm{CV} 1$ and the revertant strain CV5 were similar to the wild-type strain SC5314, which showed mycelial structures indicating hyphal growth (Fig. 4a). The hyphal cells in the colonies were counted microscopically. The colonies of the 
null mutant strain contained nearly $100 \%$ yeast cells. Those of SC5314, CV1 and CV5 contained about $95 \%$ true hyphae.

Defective hyphal growth of the vac1 null mutant strain CV3 was also observed on solid medium supplemented with serum. Under these conditions the colonies do not form mycelial structures, but show a rough surface (Fig. $4 \mathrm{~b}$ ). The different cell types that form these colonies were counted. About $20 \%$ of the null mutant cells formed true hyphae, $60 \%$ pseudohyphae, and $20 \%$ yeast cells (data not shown). Again, colonies of the wild-type strain and strains CV1 and CV5 showed about $95 \%$ true hyphae.

In liquid Spider medium as well as liquid medium supplemented with serum, hyphal growth of the C. albicans vac1 null mutant strain was induced and the time-course of hyphal development did not show significant differences from the wild-type strain (data not shown).

Hyphal development is also induced by microaerophilic conditions in an agar matrix. Following growth in such a matrix for $120 \mathrm{~h}$, the vac1 null mutant strain CV3 showed hyperfilamentation (Fig. 4c): $100 \%$ mycelium-forming colonies were observed. The wild-type strain SC5314 showed $12 \%$, the heterozygous mutant strain CV1 $8 \%$, and the revertant strain CV5 6\% mycelium-forming colonies (Fig. 4c).

In addition, a shift in $\mathrm{pH}$ was used for hyphal induction. Under these conditions the vac1 null mutant strain CV3 showed delayed hyphal induction. After $2 \mathrm{~h}$ the null mutant strain showed $25 \%$ true hyphae, as compared to $85 \%$ for the wild-type strain. After $3 \mathrm{~h}$ the percentages of hyphae for the vac1 null mutant strain (81\%) and wild-type strain (95\%) were similar (Fig. $4 \mathrm{~d}$ ).

The dimorphic growth was restored in all tested conditions by reintroducing one $V A C 1$ allele into the $v a c 1$ null mutant strain (CV5, Fig. 4a-d). This reconstitution clearly confirms that the defective phenotypes of the vac1 null mutant strain CV3 are associated with deletion of VAC1. The nearly identical phenotype of the wild-type strain, the heterozygous mutant strain and the revertant strain indicates that the different position of the URA3 gene and a possible reduction of transcription of URA3 gene does not affect the phenotypes of the null mutant strain, because the position of the URA3 gene in the null mutant strain is identical to the position in the heterozygous strain.

\section{Vac1p contributes to chlamydospore formation in C. albicans}

The affected hyphal growth of the vac1 null mutant strain inspired us to investigate the potential involvement of Vaclp in another morphogenetic switch in C. albicans. Nutrient-limited conditions induce the formation of thickwalled cells, called chlamydospores (Odds, 1988); these form at the end of elongated suspensor cells that are attached to hyphae. Growth of chlamydospores is induced in the dark under nutrient-deprived oxygen-limited conditions at low temperature on rice agar. In addition, chlamydospore induction occurs upon blockage of hyphae formation (Torosantucci \& Cassone, 1983; Nobile et al., 2003). The vac1 null mutant CV3 was completely unable to form either chlamydospores or hyphae on rice agar (Fig. 5). These morphogenetic defects were also observed in liquid rice agar. The heterozygous mutant strain CV1 was similar to the wild-type strain SC5314 in chlamydospore formation, and the ability to form chlamydospores was restored by introduction of the VAC1 gene into the mutant strain (CV5).

\section{Adhesion to epithelial human cells and secretion of aspartyl proteinases are decreased in the vac1 null mutant}

Adhesion of C. albicans to host epithelial and endothelial cells is considered a prerequisite for virulence and commensal existence. To investigate an involvement of Vaclp in adhesion, binding of the vac1 null mutant strain CV3 to human vaginal epithelial cells was tested. The vac1 null mutant strain showed reduced adhesion $(38 \% \pm 12 \%)$ compared to the wild-type strain SC5314 (100\% $\pm 19 \%)$ (Fig. 6a). This attenuation indicates a role of Vaclp in yeast adhesion to host cells. The adhesion of the heterozygous mutant strain CV1 $(90 \% \pm 25 \%)$ and the revertant strain CV5 $(80 \% \pm 16 \%)$ did not show significant differences from the wild-type strain (Fig. 6a).

Secretion of aspartyl proteinases (Saps) is considered relevant for virulence (Naglik et al., 2003; Schaller et al., 2003). Therefore, secretion of Saps, mainly Sap2p, was
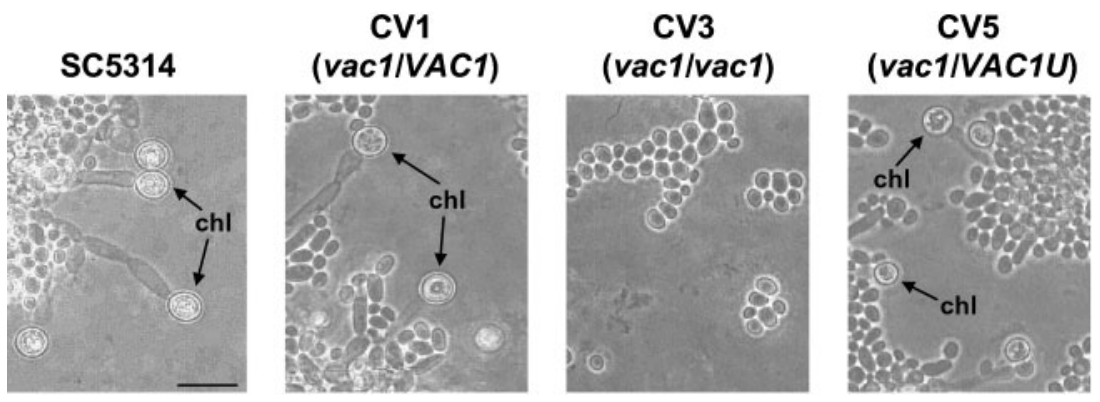

Fig. 5. Chlamydospore formation is defective in the vac1 null mutant strain. Chlamydospore formation in wild-type strain SC5314, heterozygous mutant strain CV1, vac1 null mutant strain $\mathrm{CV} 3$ and VAC1 revertant strain CV5 is shown. 
(a)

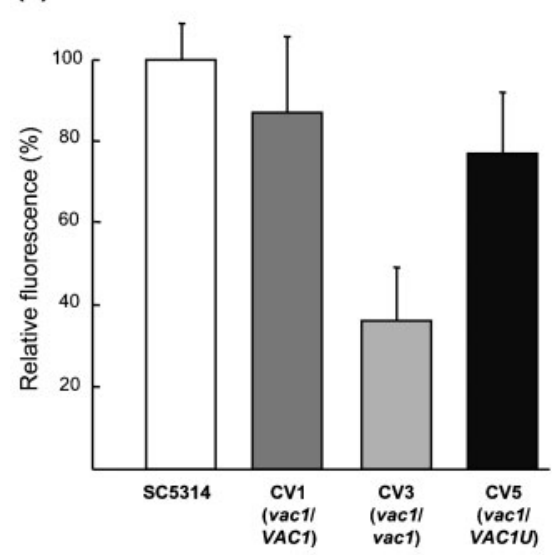

(b)

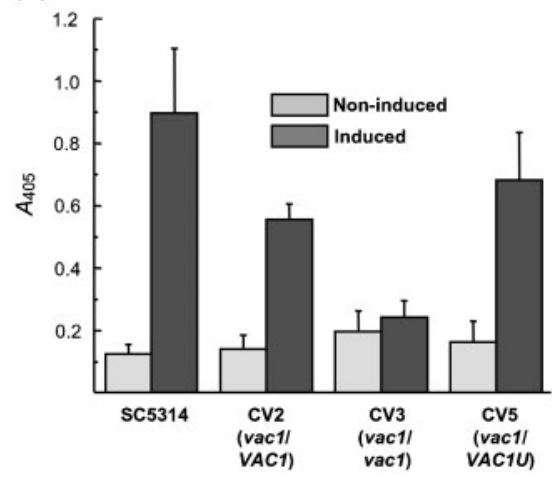

Fig. 6. The C. albicans vac1 null mutant shows affected adhesion and Sap secretion. (a) Adhesion of C. albicans vac1 mutant strains on vaginal cell line SK-LMS-1 detected by a microtest plate fluorescence assay. Adhesion values were determined after $2 \mathrm{~h}$ co-incubation of $\mathrm{C}$. albicans and epithelial cells by Calcofluor white staining and fluorescence measurement. For comparison, adhesion of wild-type strain SC5314 on SK-LMS-1 cells was set to $100 \%$ in each experiment. For the wild-type strain and vac1 null mutant strain CV3, the bars represent the means $\pm S D$ of 60 separate readings in three experiments; for $\mathrm{CV} 1$ and $\mathrm{CV} 5$, the bars represent the means $\pm S D$ for 18 separate readings in one experiment. The difference between wild-type strain SC5314 and strain CV3 was considered significant by Student's $t$-test $(P<0.025)$. No significant difference was found between SC5314 and strain CV1 or strain CV5. (b) Sap secretion of wild-type strain SC5314, heterozygous mutant strain CV1, vac1 null mutant strain CV3, and heterozygous revertant strain CV5 under Sapinducing conditions, examined by an ELISA assay. One representative experiment out of two. The error bars represent SD.

analysed in the vac1 null mutant strain CV3. Sap secretion was reduced in this strain, whereas the heterozygous mutant strain CV1 and the revertant strain CV5 showed similar secretion to the wild-type strain SC5314 (Fig. 6b). These results suggest that Vaclp affects the secretion of Sap proteinases, probably by regulating their vesicular transport and/or exocytosis.
Vac1p is required for virulence of $C$. albicans in a mouse model of systemic candidiasis

Three factors that play an important role in pathogenesis of C. albicans are affected in the vac1 null mutant strain. The virulence of the vac1 mutant strains CV1, CV3 and CV5 was therefore assayed in a mouse model of systemic candidiasis. The vac1 null mutant strain CV3 was avirulent: mice infected with $5 \times 10^{6} \mathrm{CV} 3$ cells survived during the complete course of the experiment (Fig. 7a). In contrast, all mice infected with the wild-type strain SC5315 died after 8 days. The heterozygous mutant strain $\mathrm{CV} 1$ and the revertant strain CV5 showed virulence comparable to that of the wild-type strain (Fig. 7a).

To rule out that the defective virulence is due to a growth defect, growth of the null mutant strain was tested under various conditions. In Sabouraud medium the vacl null mutant strain and the wild-type strain SC5314 showed

(a)

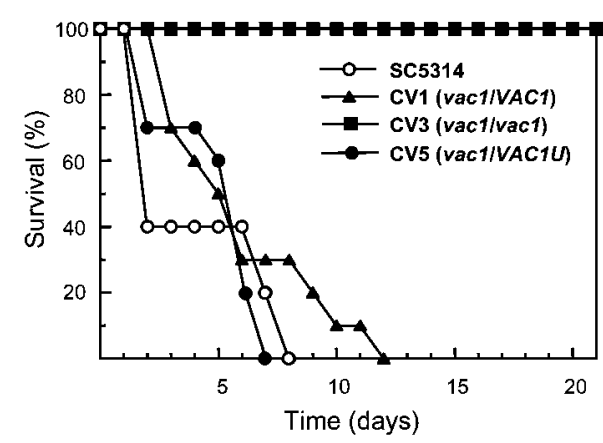

(b)

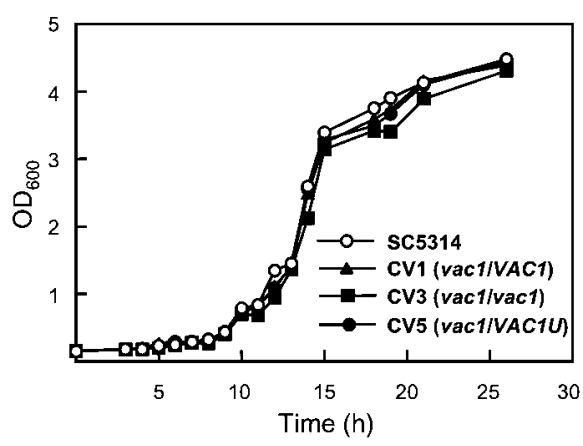

Fig. 7. The avirulence of the vac1 null mutant is linked to defective virulence factors and not to reduced growth. (a) Vac1p is involved in pathogenicity of C. albicans. Wild-type strain SC5314, heterozygous mutant strain CV1, vac1 null mutant strain CV3 and VAC1 revertant strain CV5 were tested in a mouse model of systemic candidiasis. Survival of mice infected with $5 \times 10^{6}$ cells was monitored for 20 days $(n=10)$. A $P$ value of $<0.05$ was considered as significant (Peto et al., 1977). (b) Wild-type strain SC5314, heterozygous mutant strain CV1, null mutant strain CV3 and VAC1 revertant strain CV5 show equal growth in Sabouraud medium. 
identical growth rates (Fig. 7b). Similarly, identical growth was observed in YPD medium (data not shown).

\section{DISCUSSION}

In this study we characterized the vacuolar transport protein Vaclp of C. albicans as being involved in protein transport, metal ion resistance, hyphal growth, chlamydospore formation, adhesion, secretion of Saps, and virulence. Vaclp is clearly involved in a virulence-determining pathway, and therefore represents a useful target for the screening of antifungal drugs.

The lipid kinase, but not the protein kinase activity of the multifunctional vacuolar transport protein Vps34p affects virulence of C. albicans (Günther et al., 2005). In order to elucidate the signalling pathway that mediates virulence, we analysed whether proteins with high homology to PtdIns(3)P-binding proteins of S. cerevisiae like Fablp and Vaclp are associated with virulence. A C. albicans fab1 null mutant strain has the same virulence as the wild-type strain (Augsten et al., 2002). Our work shows that another potential lipid-binding protein, Vaclp, is involved in virulence. The vac1 null mutant strain is avirulent and shows defective yeast-to-hyphae transition.

Vaclp has been shown to mediate endosomal docking of vesicles in S. cerevisiae (Peterson \& Emr, 2001). We show here that Vaclp also affects the docking of prevacuolar vesicles to the vacuole in C. albicans. This is concluded from the accumulation of the endocytotic fluorescent dye marker in prevacuolar vesicles in the vacl null mutant strain. At the stage of prevacuolar vesicles, endocytosis is linked to the CPY pathway from the Golgi to the vacuole, transiting through the prevacuolar vesicles. Thus in C. albicans Vaclp may influence both the CPY pathway and the endocytosis.

The role of Vaclp in endocytosis as shown here for $C$. albicans is in agreement with results reported for the human Vaclp homologue, which regulates fusion of endosomal vesicles with the early endosome (Stenmark et al., 1996). Further evidence for a role of Vaclp in endocytosis comes from the interaction of S. cerevisiae Vaclp and Vps33p, a protein involved in endocytosis (Subramanian et al., 2004).

A vps34 null mutant strain of C. albicans exhibits an increased sensitivity to metal ions (Kitanovic et al., 2005). The vac1 null mutant strain also shows an increased metal ion sensitivity. Thus, Vaclp and Vps34p, and consequently the vacuolar protein transport, evidently play a role in resistance to metal ions.

Vaclp influences virulence by affecting the virulence factors hyphal growth, chlamydospore formation, adhesion to host cells, and secretion of Saps. In this work we have shown that Vaclp is involved in control of hyphal growth under microaerophilic/embedded conditions. In addition, Vaclp has a mild effect on hyphal growth induced by serum or mannitol (Spider medium), or by shift to neutral $\mathrm{pH}$.
However, when vac1 null mutant cells were cultivated in liquid media no significant reduction in hyphal growth was observed, indicating that Vaclp-dependent hyphal induction pathways are induced by environmental stress, such as starvation, limited supply of oxygen or shift in $\mathrm{pH}$. The response of yeast cells to such stress conditions requires the transport and accumulation of compounds in the vacuole. The defective last step in vacuolar transport, the fusion of prevacuolar vesicles to the vacuole, in vacl null mutant cells may prevent induction of hyphal development and of several other stress-induced signalling pathways. The in vitro stress conditions that induce Vaclp-dependent pathways of hyphal growth are also found during pathogenesis of candidiasis. Therefore, the affected adaptation of the vac1 null mutant to these stress conditions, and the defect in hyphal growth, results in the avirulence of the null mutant in the mouse model of systemic candidiasis.

In addition, Vaclp is required for the morphogenetic pathway of chlamydospore formation. The vacl null mutant strain is completely unable to form chlamydospores either on a slide with rice agar covered with a coverslip or in liquid rice agar. This result, together with the hyperfilamentation of embedded cells of the vacl null mutant, may indicate that the morphogenetic regulator Efglp is affected in the vac1 null mutant, because Efg1p is required for chlamydospore development and repressed the filamentation of embedded cells (Sonneborn et al., 1999; Giusani et al., 2002). In addition, hyphal growth in response to alkaline $\mathrm{pH}$ requires Efglp (El Barkani et al., 2000). Therefore, the affected hyphal growth under alkaline conditions seems to further indicate that Vaclp influences pathways that are regulated by Efg1p.

Vaclp plays a decisive role in the secretion of Saps. The defective Saps activity in the vac1 null mutant strain is probably caused by defects in the secretory pathway from the Golgi apparatus, or the pathway from the vacuole to the cell surface, because in S. cerevisiae the secretory pathway leads to both the Golgi and the vacuole (Gurunathan et al., 2002). Such a link between the vacuolar transport and exocytosis was also shown in the C. albicans vps34 null mutant strain, where exocytotic vesicles accumulated in the periplasm (Bruckmann et al., 2001). In addition, the Vps34p and Vps11p vacuolar transport proteins are also involved in Sap secretion in C. albicans (Kitanovic et al., 2005; Palmer et al., 2003). In S. cerevisiae Vps11p, as well as Vaclp, mediates the docking of transport vesicles to the vacuolar and endosomal membrane. The synthetic interaction between a vps11ts allele and VAC1 in $S$. cerevisiae (Srivastava et al., 2000) indicates a cooperation of Vaclp and Vps11p in Sap secretion of C. albicans. Sap2p contributes to both tissue damage and invasion during systemic candidiasis (Schaller et al., 2003). Therefore, the defective Sap $2 p$ secretion very probably contributes to the avirulence of the vac1 null mutant strain.

The vac1 null mutant strain is avirulent in the mouse model of systemic candidiasis. This avirulence phenotype is 
independent of defective cell growth, since the null mutant shows almost identical growth to the wild-type strain SC5314.

In summary, the potential PtdIns(3)P-binding protein Vaclp is involved in the vacuolar vesicle transport and probably acts downstream of the PI 3-kinase Vps34p. Both the vps34 and vac1 null mutants are avirulent, and they show some similar phenotypes. Together with knowledge from $S$. cerevisiae these results indicate that Vaclp and Vps34p are involved in the same virulence-determining pathway in C. albicans.

Environmental stress affects protein transport into the vacuole of $C$. albicans. This process may induce signals for the activation of virulence signalling pathways and the start of the pathogenic life cycle. Therefore we conclude that as key regulators of vacuolar transport, Vaclp, Vps34p and Vma7p could influence virulence of $C$. albicans. Such proteins can be termed virulence-determining signal proteins.

\section{ACKNOWLEDGEMENTS}

We thank U. Stöckel and B. Weber for technical assistance in the virulence test and M. Borg-von Zeppelin for providing us with the Sap antibody FX 7-10.

\section{REFERENCES}

Augsten, M., Hübner, C., Nguyen, M., Künkel, W., Härtl, A. \& Eck, R. (2002). Defective hyphal induction on solid media of a Candida albicans phosphatidylinositol 3-phosphate 5-kinase null mutant does not lead to decreased virulence. Infect Immun 70, 4462-4470.

Boeke, J. D., LaCroute, F. \& Fink, G. R. (1984). A positive selection for mutants lacking orotidine-5' -phosphate decarboxylase activity in yeast: 5-fluoro-orotic acid resistance. Mol Gen Genet 197, 345-346.

Bruckmann, A., Künkel, W., Härtl, A., Wetzker, R. \& Eck, R. (2000). A phosphatidylinositol 3-kinase of Candida albicans influences adhesion, filamentous growth, and virulence. Microbiology 146, 2755-2764.

Bruckmann, A., Künkel, W., Augsten, K., Wetzker, R. \& Eck, R. (2001). The deletion of CaVPS34 in the human pathogenic yeast Candida albicans causes defects in vesicle-mediated protein sorting and nuclear segregation. Yeast 18, 343-353.

Burd, C. G. \& Emr, S. D. (1998). Phosphatidylinositol(3)-phosphate signaling mediated by specific binding to RING FYVE domains. Mol Cell 2, 157-162.

Burd, C. G., Peterson, M., Cowles, C. \& Emr, S. D. (1997). A novel Sec18/NSF-dependent complex required for Golgi-to-endosome transport in yeast. Mol Biol Cell 8, 1089-1104.

Cutler, J. E. (1991). Putative virulence factors of Candida albicans. Annu Rev Microbiol 45, 187-218.

Eck, R., Bergmann, C., Ziegelbauer, K., Schönfeld, W. \& Künkel, W. (1997). A neutral trehalase gene from Candida albicans: molecular cloning, characterization and disruption. Microbiology 143, 37473756.

Eck, R., Bruckmann, A., Wetzker, R. \& Künkel, W. (2000). A phosphatidylinositol 3-kinase of Candida albicans: molecular cloning and characterization. Yeast 16, 933-944.
Eck, R., Nguyen, M., Günther, J., Künkel, W. \& Zipfel, P. F. (2005). The phosphatidylinositol 3-kinase Vps34p of the human pathogenic yeast Candida albicans is a multifunctional protein that interacts with the putative vacuolar $\mathrm{H}^{+}$-ATPase subunit Vma7p. Int $J$ Med Microbiol 295, 57-66.

El Barkani, A., Kurzai, O., Fonzi, W. A., Ramon, A., Porta, A., Frosch, M. \& Mühlschlegel, F. A. (2000). Dominant active alleles of RIM101 (PRR2) bypass the $\mathrm{pH}$ restriction on filamentation of Candida albicans. Mol Cell Biol 20, 4635-4647.

Ernst, J. F. (2000a). Regulation of dimorphism in Candida albicans. Contrib Microbiol 5, 98-111.

Ernst, J. F. (2000b). Transcription factors in Candida albicans environmental control of morphogenesis. Microbiology 146, 1763-1774.

Fonzi, W. A. \& Irwin, M. Y. (1993). Isogenic strain construction and gene mapping in Candida albicans. Genetics 134, 717-728.

Gary, J. D., Wurmser, A. E., Bonangelino, C. J., Weisman, L. S. \& Emr, S. D. (1998). Fablp is essential for PI(3)P 5-kinase activity and the maintenance of vacuolar size and homeostasis. J Cell Biol 143, 65-79.

Giusani, A. D., Vinces, M. \& Kumamoto, C. A. (2002). Invasive filamentous growth of Candida albicans is promoted by Czflpdependent relief of Efglp-mediated repression. Genetics 160, 1749-1753.

Günther, J., Nguyen, M., Härtl, A., Künkel, W., Zipfel, P. F. \& Eck, R. (2005). Generation and functional in vivo characterization of a lipid kinase defective phosphatidylinositol 3-kinase Vps34p of Candida albicans. Microbiology 151, 81-89.

Gurunathan, S., David, D. \& Gerst, J. E. (2002). Dynamin and clathrin are required for the biogenesis of a distinct class of secretory vesicles in yeast. EMBO J 21, 602-614.

Horazdovsky, B., Busch, G. \& Emr, S. D. (1994). VPS21 encodes a Rab5-like GTP binding protein that is required for the sorting of yeast vacuolar proteins. EMBO J 13, 1297-1309.

Kitanovic, A., Nguyen, M., Vogl, G., Hartman, A., Günther, J., Würzner, R., Künkel, W., Wölfl, S. \& Eck, R. (2005). Phosphatidylinositol 3-kinase VPS34 of Candida albicans is involved in filamentous growth, Saps secretion, and intracellular detoxification. FEMS Yeast Res 5, 431-439.

Köhler, J. R. \& Fink, G. R. (1996). Candida albicans strains heterozygous and homozygous for mutations in mitogen-activated protein kinase signaling components have defects in hyphal development. Proc Natl Acad Sci U S A 93, 13223-13228.

Lee, K. L., Buckley, H. R. \& Campbell, C. C. (1975). An amino acid liquid synthetic medium for the development of mycelial and yeast forms of Candida albicans. Sabouraudia 13, 148-153.

Lo, H.-J., Köhler, J. R., DiDomenico, B., Loebenberg, D., Cacciapuoti, A. \& Fink, G. R. (1997). Nonfilamentous C. albicans mutants are avirulent. Cell 90, 939-949.

Naglik, J. R., Challacombe, S. J. \& Hube, B. (2003). Candida albicans secreted aspartyl proteinases in virulence and pathogenesis. Microbiol Mol Biol Rev 67, 400-428.

Nobile, C. J., Bruno, V. M., Richard, M. L., Davis, D. A. \& Mitchell, A. P. (2003). Genetic control of chlamydospore formation in Candida albicans. Microbiology 149, 3629-3637.

Odds, F. C. (1988). Candida and Candidosis. A Review and Bibliography, 2nd edn. London, UK: Baillière-Tindall.

Odds, F. C. (1994). Pathogenesis of Candida infections. J Am Acad Dermatol 31, S2-S5.

Palmer, G. E., Cashmore, A. \& Sturtevant, J. (2003). Candida albicans VPS11 is required for vacuole biogenesis and germ tube formation. Eukaryot Cell 2, 411-421. 
Peterson, M. R. \& Emr, S. D. (2001). The class C Vps complex functions at multiple stages of the vacuolar transport pathway. Traffic 2, 476-486.

Peterson, M. R., Burd, C. G. \& Emr, S. D. (1999). Vac1 coordinates $\mathrm{Rab}$ and phosphatidylinositol 3-kinase signaling in Vps45dependent vesicle docking/fusion at the endosome. Curr Biol 9, 159-162.

Peto, R., Pike, M. C., Armitage, P. \& 7 other authors (1977). Design and analysis of randomized clinical trials requiring prolonged observation of each patient. II. Analysis and examples. Br J Cancer 35, 1-39.

Poltermann, S., Nguyen, M., Günther, J., Wendland, J., Härtl, A., Künkel, W., Zipfel, P. F. \& Eck, R. (2005). The putative vacuolar ATPase subunit Vma7p of Candida albicans is involved in vacuole acidification, hyphal development and virulence. Microbiology 151, 1645-1655.

Schaller, M., Bein, M., Korting, H. C., Baur, S., Hamm, G., Monod, M., Beinhauer, S. \& Hube, B. (2003). The secreted aspartyl proteinases Sap1 and Sap2 cause tissue damage in an in vitro model of vaginal candidiasis based on reconstituted human vaginal epithelium. Infect Immun 71, 3227-3324.

Sonneborn, A., Bockmuhl, D. P. \& Ernst, J. F. (1999). Chlamydospore formation in Candida albicans requires the Efglp morphogenetic regulator. Infect Immun 67, 5514-5517.

Srivastava, A., Woolford, C. A. \& Jones, E. W. (2000). Pep3p/Pep5p complex: a putative docking factor at multiple steps of vesicular transport to the vacuole of Saccharomyces cerevisiae. Genetics 156, 105-122.

Stenmark, H. \& Aasland, R. (1999). FYVE-finger proteins - effectors of an inositol lipid. J Cell Sci 112, 4175-4183.

Stenmark, H., Aasland, R., Toh, B.-H. \& D’Arrigo, A. (1996). Endosomal localization of the autoantigene EEA1 is mediated by a zinc-binding FYFE finger. J Biol Chem 271, 24048-24054.
Subramanian, S., Woolford, C. A. \& Jones, E. W. (2004). The Sec1/ Munc18 protein, Vps33, function at the endosome and the vacuole of Saccharomyces cerevisiae. Mol Biol Cell 15, 2593-2605.

Swoboda, R. K., Bertram, G., Delbruck, S., Ernst, J. F., Gow, N. A., Gooday, G. W. \& Brown, A. J. (1994). Fluctuations in glycolytic mRNA levels during morphogenesis in Candida albicans reflect underlying changes in growth and are not a response to cellular dimorphism. Mol Microbiol 13, 663-672.

Tall, G. G., Hama, H., DeWald, D. B. \& Horazdovsky, B. F. (1999). The phosphatidylinositol 3-phosphate binding protein Vaclp interacts with a Rab GTPase and a Seclp homologue to facilitate vesiclemediated vacuolar protein sorting. Mol Biol Cell 10, 1873-1889.

Torosantucci, A. \& Cassone, A. (1983). Induction and morphogenesis of chlamydospores in an agerminative variant of Candida albicans. Sabouraudia 21, 49-57.

Vida, T. A. \& Emr, S. D. (1995). A new vital stain for visualizing vacuolar membrane dynamics and endocytosis in yeast. J Cell Biol 128, 779-792.

Webb, G. C., Hoedt, M., Poole, L. J. \& Jones, E. W. (1997). Genetic interactions between a pep7 mutation and the PEP12 and VPS45 genes: evidence for a novel SNARE component in transport between the Saccharomyces cerevisiae Golgi complex and endosome. Genetics 147, 467-478.

Weisman, L. S. \& Wicker, W. (1992). Molecular characterization of $V A C 1$, a gene required for vacuole inheritance and vacuole protein sorting. J Biol Chem 267, 618-623.

Wurmser, A. E. \& Emr, S. D. (1998). Phosphoinositide signaling and turnover: PtdIns(3)P, a regulator of membrane traffic, is transported to the vacuole and degraded by a process that requires lumenal vacuolar hydrolase activities. EMBO J 17, 4930-4942.

Yanisch-Perron, C., Vieira, J. \& Messing, J. (1985). Improved M13 phage cloning vectors and host strains: nucleotide sequence of M13mp18 and pUC19 vectors. Gene 33, 103-119. 